\title{
Efficient Cooling Method for a Cu Coil in an Induction Cooker by Using an Insulation Sheet
}

\author{
Jonghan Kwon ${ }^{1}$, Yoon Jae $\mathrm{Nam}^{2}$, K. H. Shin ${ }^{3}$, and S. H. Lim ${ }^{1,2 *}$ \\ ${ }^{1}$ Department of Materials Science and Engineering, Korea University, Seoul 136-713, Korea \\ ${ }^{2}$ Department of Nano-Semiconductor Engineering, Korea University, Seoul 136-713, Korea \\ ${ }^{3}$ Department of Multimedia Engineering, Kyungsung University, Busan 608-736, Korea
}

(Received 28 July 2010, Received in final form 3 December 2010, Accepted 3 December 2010)

\begin{abstract}
A silica aerogel sheet with a very low thermal conductivity is used to suppress the temperature increase of the $\mathrm{Cu}$ coil in an induction cooker by reducing the heat flow from the heat source (cooking pot). It is found that the temperature of the $\mathrm{Cu}$ coil is reduced significantly by the insertion of an insulation sheet between the heat source and the $\mathrm{Cu}$ coil, demonstrating the effectiveness of the insulation sheet in the suppression of the heat flow between the cooking pot and the coil. Furthermore, the temperature of the cooking pot increases more rapidly with the use of the insulation sheet, allowing for an increased efficiency of the induction cooker.
\end{abstract}

Keywords : induction cooker, aerogel sheet, thermal insulation

\section{Introduction}

In recent years, induction cookers have found an increasing and widespread use because they have many advantages over conventional cooking appliances based on gas or direct Joule (electrical) heating. Compared with gas cookers, induction cookers are safer because there is no risk of a gas explosion, and they are also cleaner, being free from $\mathrm{CO}$ and $\mathrm{CO}_{2}$ gases because they do not require an oxygen consumption during their operation. Furthermore, induction cookers have a significantly higher efficiency $(>90 \%)$ than conventional electric cookers [1]. The operation of induction cookers is based on Faradays law. A magnetic field (frequently called an Ampere field) is generated by a $\mathrm{Cu}$ coil through which ac current flows. In most cases, the field is amplified by placing a magnetic material (usually $\mathrm{Mn}-\mathrm{Zn}$ ferrite due to the high operational frequency of several tens of $\mathrm{kHz}$ ) below the coil. Eddy currents are then induced in a ferric cooking pot (usually placed above the coil), causing it to heat up the pot through inductive heating [2]. It is clear from the basic operational principle that the $\mathrm{Cu}$ coil plays an important role in the operation of induction cookers. For the reliable and efficient operation of the cookers it is

*Corresponding author: Tel: $+82-2-3290-3285$

Fax: +82-2-928-3584, e-mail: sangholim@korea.ac.kr important to suppress the increase of the temperature at the $\mathrm{Cu}$ coil as much as possible [3]. However, the $\mathrm{Cu}$ coil is heated up during operation due to the following two main reasons. One is the Joule heating caused by the current that flows through the $\mathrm{Cu}$ coil $(\mathrm{Cu}$ loss). The other main reason is the heat flow returning from the hot cooking pot. Since the temperature of a cooking pot can reach $\sim 420^{\circ} \mathrm{C}$ [4], the temperature of coil increase due to heat transfer can be significant. The main aim of this paper is to suppress this heat transfer by placing an insulation sheet between the cooking pot and the $\mathrm{Cu}$ coil.

\section{Experimental}

Fig. 1 displays a schematic view of an induction cooker, showing the key components including the $\mathrm{Cu}$ coil, the electronic circuit, and the ceramic glass upon which the cooking pot is placed. Another important component is the cooling fan, which is used to cool down the $\mathrm{Cu}$ coil and the circuit. A notable side effect caused by the fan is an unwanted cooling of the cooking glass thereby cooling the cooking pot. The cooling fan is usually located to one side of the induction cooker (as seen in the upper panel of Fig. 1), leading to uneven cooling with a temperature disparity. There are two different ways to place an insulation sheet between the cooking pot and the $\mathrm{Cu}$ coil (see the lower panel of Fig. 1); either just below the ceramic glass 

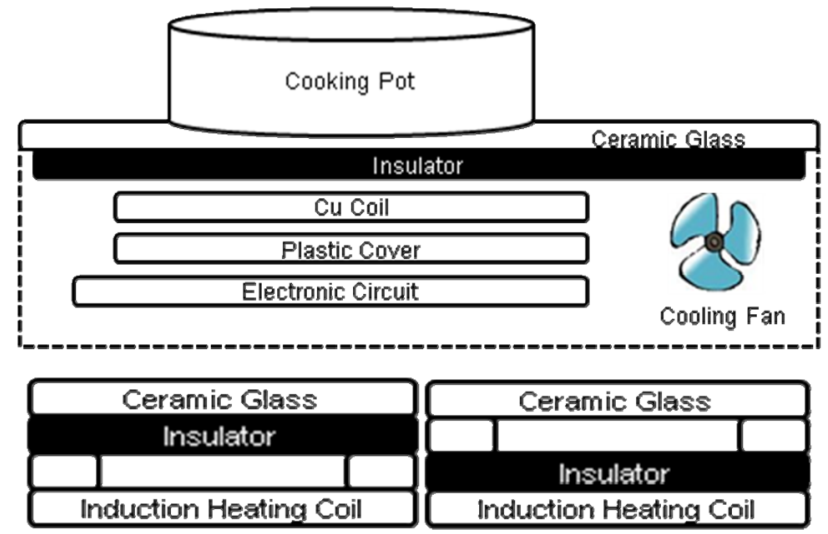

Type A

Type B

Fig. 1. The upper panel shows a schematic diagram showing an induction cooker, while the lower panel illustrates the two different ways (types A and B) of placing an insulation sheet between the ceramic glass and the $\mathrm{Cu}$ coil.

(type A) or just above the $\mathrm{Cu}$ coil (type B). Both methods were tried in this study and the preliminary results showed that type A was better than type B in the suppression of the temperature increase in the $\mathrm{Cu}$ coil. This is because in type A, where the insulator is in direct contact with the ceramic glass, the unwanted cooling of the ceramic glass by the cooling fan is significantly reduced. Therefore, the results are only shown for type $\mathrm{A}$ in this study. The insulation sheet used in this study, which was provided by Aspen Aerogels Inc. [5], was made from a silica $\left(\mathrm{SiO}_{2}\right)$ aerogel. The important physical properties of the insulation sheet are summarized in Table 1. The performance of the insulation sheet was evaluated by measuring the increase of the temperature of the $\mathrm{Cu}$ coil. The measurement of the temperature was done by using thermocouples attached to 8 different places of the $\mathrm{Cu}$ coil, a photo of which is shown in Fig. 2. The large number of measurement positions was necessary because the cooling fan is located off to the side causing a wide temperature distribution. However, we report on only the 3 typical places (locations 1, 2, and 3) as indicated in Fig. 2. A commercial induction cooker (model \# BKP-22, Dipo Electronics, Korea [6]) was used for the experiment. We used the following experimental procedure. A cooking pot contain-

Table 1. Some important physical properties of the insulation sheet made from a silica aerogel.

\begin{tabular}{lc}
\hline \hline Thickness $(\mathrm{mm})$ & 2 \\
Thermal conductivity $(\mathrm{W} / \mathrm{m} \cdot \mathrm{K})$ & 0.155 \\
Density $\left(\mathrm{g} / \mathrm{cm}^{3}\right)$ & 0.17 \\
Average pore size $(\mathrm{nm})$ & 10 \\
\hline
\end{tabular}

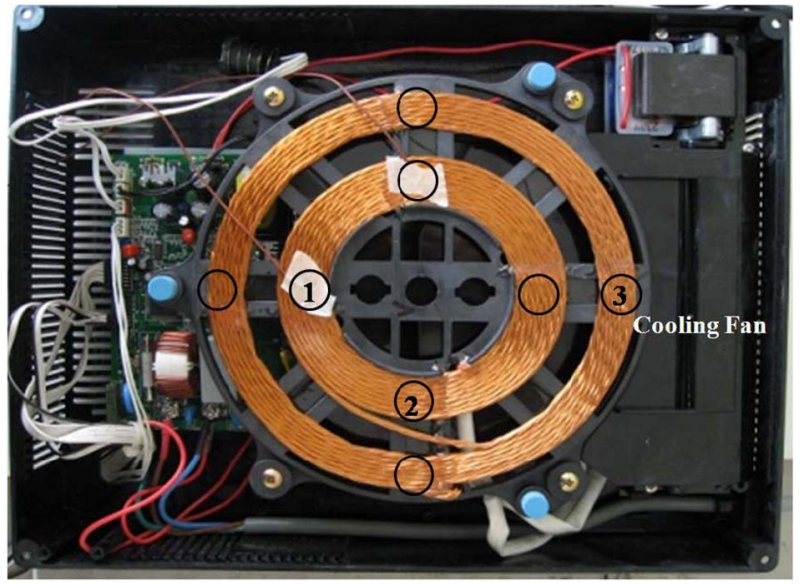

Fig. 2. A photograph showing the $\mathrm{Cu}$ coil used in this study. The lateral dimensions of the photograph are $370 \mathrm{~mm} \times 300$ $\mathrm{mm}$. The temperature was measured at 8 different places, but the results are only shown here for three typical locations 1,2 , and 3. The cooling fan is located on the right side of the coil.

ing water or soybean oil was heated at maximum power (approximately $2.4 \mathrm{~kW}$ ), maintaining it throughout the experiment so that the water or oil was boiled (and hence evaporated) during most of the temperature measurements. Obviously, this experimental condition was significantly harsher than the usual operational conditions where the power is suitably regulated to maintain the desired temperature. The soybean oil was produced by a local company (CJ Cheiljedang Corp., Korea [7]) and some important properties are: a flash point of 262 with a density of 0.924 $\mathrm{g} / \mathrm{cc}$. Considering that the water or the oil was evaporated during the measurement, a large amount of water $(4 \mathrm{~L})$ or oil $(3.6 \mathrm{~L})$ was used to make the temperature measurement time.

\section{Results and Discussion}

The results for the temperature of the $\mathrm{Cu}$ coil as a function of measurement time are shown in Figs. 3(a) and (b) for oil and water, respectively. The temperature before heating is 25 in both cases. In the case of the oil (Fig. $3(\mathrm{a})$ ), the results are shown for the three typical locations (locations 1, 2, and 3, as referenced by Fig. 2). In the case of the water (Fig. 3(b)), however, the results are shown only for location 2. It is clear from Fig. 2 that the temperature at location 1 should be the highest because the cooling fan is located on the opposite side, while the temperature at location 3 should be the lowest due to the proximity of the cooling fan. An intermediate temperature is expected at location 2. This feature is clearly seen from the results shown in Fig. 3(a). The temperature at location 

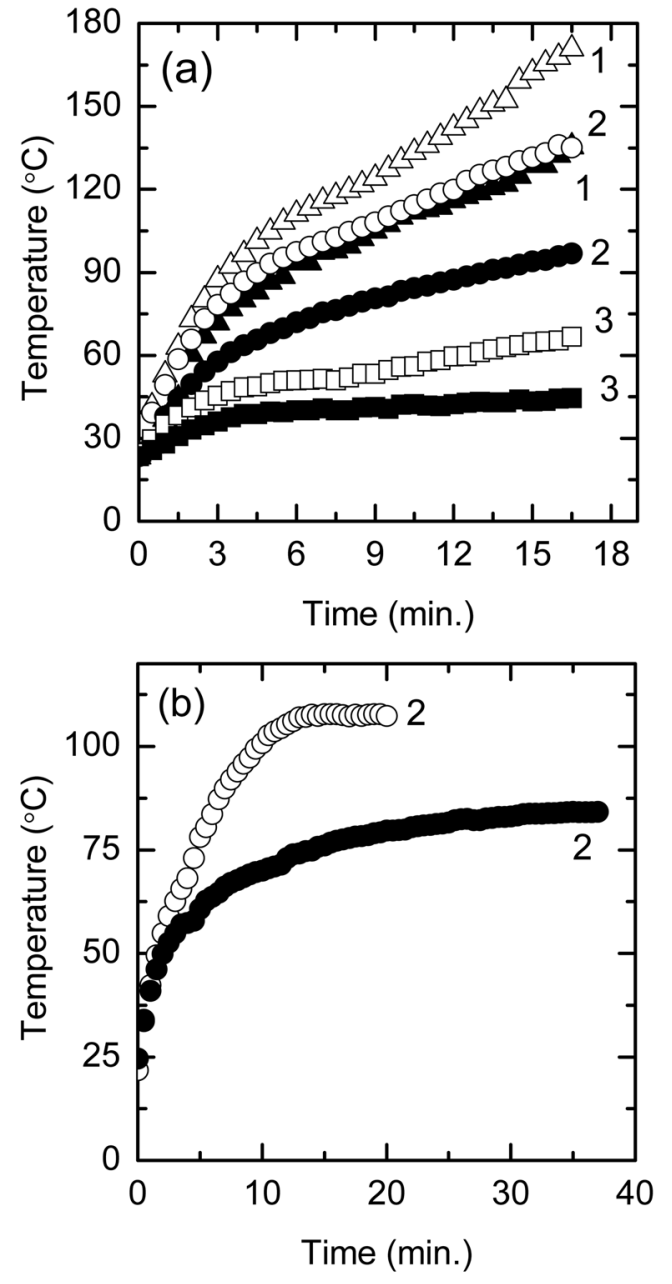

Fig. 3. The results for the temperature of the $\mathrm{Cu}$ coil as a function of measurement time when the substance in the cooking pot is (a) soybean oil or (b) water. The numbers at the curves indicate measurement locations as shown in Fig. 2. The results in unfilled symbols were obtained without using the insulation sheet while those in filled symbols were obtained using the insulation sheet.

1 , the results of which are denoted by triangles, increases continuously with the increase of the measurement time, finally reaching $170.8^{\circ} \mathrm{C}$ at $16.5 \mathrm{~min}$, the longest time examined in this study, without insulation (unfilled triangles). This final temperature of $170.8^{\circ} \mathrm{C}$ is considered to be quite high, considering that the maximum temperature limit for the insulation sheet is approximately $180^{\circ} \mathrm{C}$. However, when the insulation sheet is inserted, the results (filled triangles) show a significant decrease in the coil temperature. In this case, the temperature is $135.2^{\circ} \mathrm{C}$ at the longest measurement time of $16.5 \mathrm{~min}$. These results clearly indicate the significant role played by the insulation sheet in suppressing the temperature increase of the $\mathrm{Cu}$ coil. An equally large decrease in the temperature is observed at the other measurement locations. Specifically, at the longest measurement time of $16.5 \mathrm{~min}$, the temperature is reduced from $135.5^{\circ} \mathrm{C}$ to $96.9^{\circ} \mathrm{C}$ at location 2 , and reduced from $66.8^{\circ} \mathrm{C}$ to $44.6^{\circ} \mathrm{C}$ at location 3. One notable feature from the temperature profiles shown in Fig. 3(a) is that the rate of the temperature increase is initially rather steep up to $\sim 3 \mathrm{~min}$, followed thereafter by a slower increase. It was originally thought that this change in the slope had something to do with a phase change (such as boiling) in the oil, but no obvious connection was observed, rendering the reason for the slope change unclear at the moment. As was mentioned in the previous section, a maximum power of $2.4 \mathrm{~kW}$ was continuously supplied to the induction cooker. This indicates that, once the oil starts to boil, it continues to boil (and hence evaporate) during the measurement and, furthermore, the temperature of the oil itself increases continuously with time. Resultantly, the heat from the cooking pot increases with time, so does the temperature of the $\mathrm{Cu}$ coil.

A more striking difference was observed in the case of the water depending on the use of the insulation sheet (Fig. 3(b)). The temperature of the $\mathrm{Cu}$ coil increases quickly at the initial stage, and reaches a saturation value of $\sim 107^{\circ} \mathrm{C}$ at $\sim 10 \mathrm{~min}$ when the insulation sheet is not installed. Unlike oil, it is important to note that the temperature increase saturates after a certain time. This is because, in the case of water which has a simple and strong molecular bonding, the molecular structure of water remains unchanged and so the energy supplied from the induction cooker is mainly used for the phase transition from water to steam. It is therefore expected that the temperature of the cooking pot and also that of the $\mathrm{Cu}$ coil will remain nearly constant after saturation. However, in the case of oil, which has more complex and larger molecules than water, the molecular structure itself changes as the energy is continuously supplied after boiling so that the temperature of oil can increase up to its flash point $\left(262^{\circ} \mathrm{C}\right)$. The temperature increase is significantly reduced when the insulation sheet is installed. Specifically, the temperature increases rather quickly initially (but with a slower rate) and starts to saturate after $5 \mathrm{~min}$ at a value of $\sim 85^{\circ} \mathrm{C}$, which is significantly smaller than the value of $\sim 107^{\circ} \mathrm{C}$ observed for the case without the insulation sheet. This confirms again the significant role the insulation sheet in reducing the heat transfer from the cooking pot to the $\mathrm{Cu}$ coil.

So far, the role of the insulation sheet has been discussed in the reduction of the heat transfer from the cooking pot to the $\mathrm{Cu}$ coil. Then, it is of interest to examine how the use of the insulation sheet affects the temperature of the water or the oil in the cooking pot. This is because, 


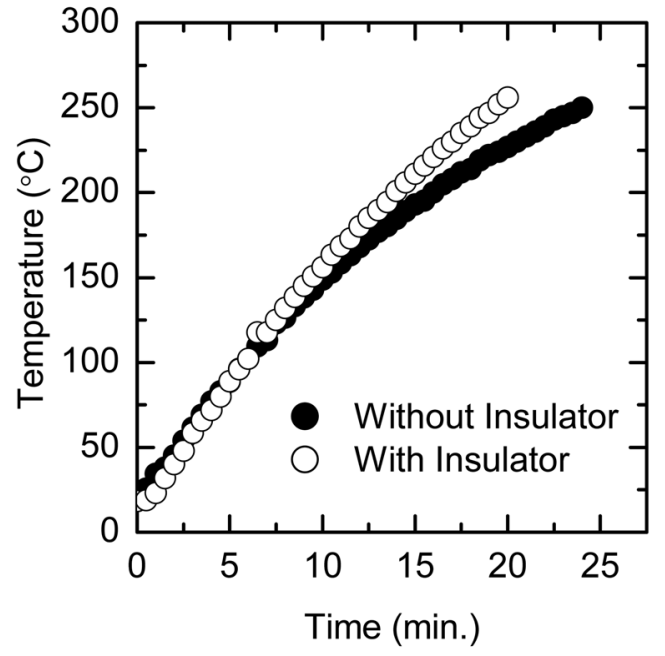

Fig. 4. The results for the temperature of the soybean oil in the cooking pot as a function of measurement time. The results in unfilled circles were obtained without using the insulation sheet while those in filled circles were obtained using the insulation sheet.

from the structure of the induction cooker as shown in Fig. 1, the cooling fan will be expected to cool down the ceramic glass and hence the cooking pot, as well as the $\mathrm{Cu}$ coil and the electronic circuit. This will have an adverse effect on the efficiency of the induction cooker. Fig. 4 shows the results for the temperature of oil as a function of measurement time. From Fig. 4, it can be seen that the temperature of the oil increases more rapidly when the insulation sheet is inserted. Specifically, as the time increases from 0 to $20 \mathrm{~min}$, the temperature of oil increases from $18.4^{\circ} \mathrm{C}$ to $256^{\circ} \mathrm{C}$ when the insulation sheet is inserted, but, with the same time span, it increases from $24.4^{\circ} \mathrm{C}$ to only $227^{\circ} \mathrm{C}$ when the insulation sheet is not used. Note that the initial temperatures of the oil differ slightly. The experimental run using the insulation sheet was carried out first, followed by the second experimental run without using the insulation sheet. The time interval between these two experimental runs should have been long enough so that the initial temperatures of the oil were identical to each other. However, for practical reasons, the time interval between the experimental runs was not long enough, causing the slight difference of the initial temperature. This slight difference in the initial temperatures, however, does not cause any problem in analyzing the result. At the longest time of $20 \mathrm{~min}$, the temperature of oil reaches $256^{\circ} \mathrm{C}$, which is close to its flash point $\left(262^{\circ} \mathrm{C}\right)$. This is the reason why the experiment was stopped at this time. Note that the experiment was terminated earlier when the insulation sheet was used, because the temperature of the oil approached the maximum limit earlier. Obviously, this is due to the prevention (or reduction) of the adverse effects of the cooling fan. Namely, the ceramic glass holding the cooking pot is cooled less by the cooling fan with the application of the insulation sheet. Another reason is from the reduction of the heat transfer from the cooking pot. One aspect of this effect, to reduce the temperature of the $\mathrm{Cu}$ coil, was already discussed. Another aspect of this effect is to increase the temperature of the cooking pot and hence the efficiency of the induction cooker, because more heat remains in the cooking pot.

\section{Conclusions}

The $\mathrm{Cu}$ coil plays an important role in the operation of an induction cooker by generating a magnetic field (known as the Ampere field). An efficient operation requires that the temperature of the $\mathrm{Cu}$ coil be maintained as low as possible. In an effort to achieve this goal, a silica aerogel sheet with a very low thermal conductivity was inserted between the heat source (cooking pot) and the $\mathrm{Cu}$ coil to suppress the heat flow transferred from the cooking pot to the coil. The performance of the insulation sheet was tested by measuring the temperature of the $\mathrm{Cu}$ coil under the severe conditions of applying the maximum power throughout the experiment. A significant reduction of the temperature of the $\mathrm{Cu}$ coil was accomplished with the insertion of the insulation sheet. For example, the temperature of the $\mathrm{Cu}$ coil, at the intermediate location 2, was reduced with the use of the insulation sheet from 135.5 to 96.9 at the longest measurement time of $16.5 \mathrm{~min}$, using soybean oil as the substance in the cooking pot. A more significant reduction of the temperature was observed when water was used as the substance in the cooking pot. These results clearly demonstrate the effectiveness of the insulation sheet in suppressing the heat flow from the cooking pot to the $\mathrm{Cu}$ coil. Furthermore, it was found that the insulation sheet plays the additional role of increasing the temperature of the cooking pot itself (and hence the substances within the pot). This result is significant because the efficiency of the induction cooker is increased by the use of the insulation sheet. This increase of the efficiency is due to the reduction of the adverse effect of the cooling fan that cools down the cooking pot as well as the $\mathrm{Cu}$ coil with its accompanying electronic circuit.

\section{Acknowledgments}

This research was financially supported by a grant to MEMS Research Center for National Defense funded by Defense Acquisition Program Administration. 


\section{References}

[1] M. Newborough, S. D. Probert, and M. Newman, Appl. Energ. 3, 37 (1990).

[2] T. Davies and P. Simpson, Induction Heating Handbook, McGraw-Hill, London (1979).

[3] H. H. J. M. Janssen, E. J. W. ter Maten, and D. van Hou- welingen, IEEE Trans. Magn. 30, 3331 (1994).

[4] H. C. Chen and K. H. Huang, Int. J. Appl. Electromagn. Mech. 28, 413 (2008).

[5] Aspen Aerogel Inc., http://www.aerogel.com.

[6] Dipo Electronics, http://www.dipoelec.com.

[7] CJ Cheiljedang Corporation, http://english.cj.net. 